\title{
Performance Analysis for Major Chain Convenience Stores in Taiwan
}

\author{
Spring C. Hsu \\ Dept. of Business Administration, China University of Science and Technology \\ No. 245, Academia Rd., Sec. 3, Taipei City 115, Taiwan \\ E-mail: clhsu@cc.cust.edu.tw
}

Received: November 12, 2017 Accepted: December 5, 2017 Published: December 7, 2017

doi: $10.5296 /$ jsss.v5i1.12246

URL: http://doi.org/10.5296/jsss.v5i1.12246

\begin{abstract}
Taiwan is one of the highest density market of convenience stores in the world, and most of the stores belong to certain major chain convenience store systems. Therefore, it is important to analyze the operating performance of these chain convenience stores. This study selects the four largest domestic chain convenience store systems in Taiwan, as 7-Eleven, FamilyMart, Hi-Life, and OK-Mart, for the operational efficiency and comparative analysis. Moreover, this study deploys the data envelopment analysis (DEA) efficiency measurement method for measuring efficiency of these chain convenience stores because of its proved effectiveness in many manufacturing and service operating efficiency analysis. The results of this study show that the operating performance of 7-Eleven is the most efficient due to the economy of scales. However, 7-Eleven should beware of the followed FamilyMart, which owns the $85 \%$ relative efficiency compared to 7-Eleven, and may catch up with 7-Eleven if it increases its number of stores.
\end{abstract}

Keywords: Chain convenience stores, Efficiency, DEA

\section{Introduction}

The term convenience stores refers to the service-oriented small or medium-sized store that provide goods such as fast foods, beverages, daily necessities and other necessary services. Moreover, to better meet the needs of customers, many convenience stores run in chain type business, and the representative chain convenience stores in Taiwan are 7-Eleven, FamilyMart, Hi-Life and OK-Mart. The chain convenience stores have been able to easily expand the business and scope of the services by the advantages of dense channels and the large-scale of operation. In fact, the advent of the convenience stores does not only change 
the consumption habits of customers, it also brings people's life to a completely new era.

The scope of this study is to select the existing four major chain convenience stores in Taiwan for efficiency comparison and discussion, and the research data come from the most recent year 2016. Moreover, this study applies the data envelopment analysis (DEA) to analyze the efficiency of these chain convenience stores. The method of data envelopment analysis for measuring efficiency has been widely applied in the comparative analysis on the operating efficiency in many manufacturing and service industries. This method cannot only calculate a quantitative efficiency index for the specific company, but can also show the relatively inefficient indexes for other companies. Furthermore, the numerical data in this study are obtained through the private job bank database, the official websites of the research chain convenience stores, and the Department of Commerce, Ministry of Economic Affairs, Taiwan.

\section{Methodology}

Data envelopment analysis (DEA) is an application of linear programming, mainly applied for analyzing several similar types of service units, such as banks, hospitals, restaurants, schools, department stores, and many other industries. The data envelopment analysis can show whether a particular unit is less productive or inefficient than other units (Taylor III, 2009). For the development of data envelope analysis, it is originated from Farrell in 1957, he proposed the original model of efficiency analysis for fixed production scale conditions; then in 1978, Charnes, Cooper and Rhode developed a CCR model to further explore efficiency issues, and this method extends the ability of Farrell's model, i.e., the CCR model can evaluate multiple outputs. Moreover, in 1984, Banker, Charnes and Cooper proposed the BCC model to further consider the case for non-fixed production scale conditions.

The data envelopment analysis can measure efficiency based on the concept of the optimal level of Pareto efficiency, which means no one can increase the interests without compromising others. Moreover, the data envelopment analysis uses the product frontier as the basis for measuring the efficiency. The changes in output efficiency show the result of efficient or not for the decision-making units (DMUs). If the efficiency of a decision-making unit is on the frontier, then the efficiency value is set as one, otherwise the efficiency values are less than one.

Furthermore, the basic procedure to apply the data envelopment analysis model can be defined in three steps as "definition of the problem and the choice of decision-making units," "selection of the relevant and reasonable inputs and outputs" and "implementation of the DEA model and assessment making," as shown in Figure 1. 


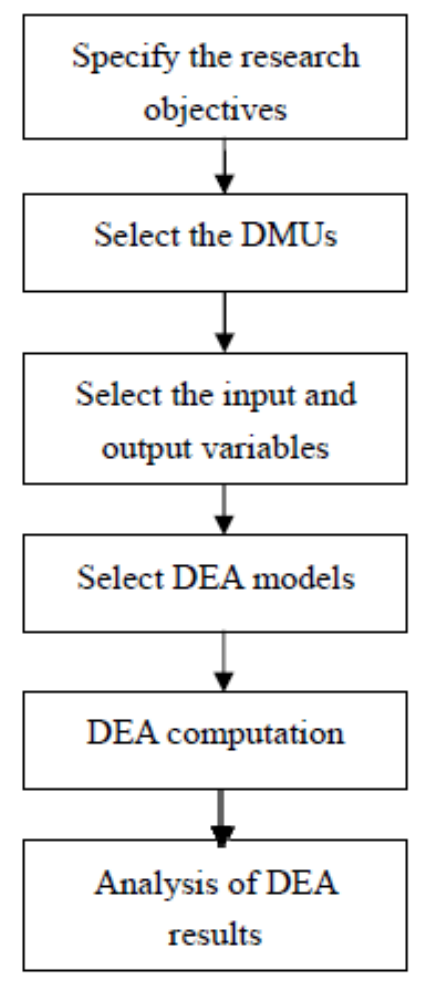

Figure 1. The DEA Procedures

In recent years, applications of data envelopment analysis in the relevant literature can be found in services, manufacturing and other fields. For the studies on the performance of the banking industry, Saha and Ravisankar (2000) explored the performance of the Indian banking sector before and after the financial regulations in 1990. Sathye (2003) also explored the performance of overall Indian banks by means of data envelopment analysis, and found that public banks were more efficient than private ones, as opposed to the situation in many other countries.

For other applications of the data envelopment analysis, Ramanathan (2001) explored the performance of different energy sources, by data envelopment analysis method. Eilat et al. (2006) evaluated the performance of $R \& D$ projects with the data envelopment analysis method. Hamdan and Roger (2008) also evaluated the performance of third-party logistics by data envelopment analysis method. Moreover, Hosseinzadeh et al. (2016) identified the balance of efficiency for 33 Australian mining firms over the period 2008-2014 using data envelopment analysis method. In general, these studies show that data envelopment analysis is a popular and useful method in efficiency and performance analysis.

\section{Numerical Analysis}

The convenience stores market in Taiwan is now dominated by the four major chain systems as the 7-Eleven, FamilyMart, Hi-Life and OK-mart. Therefore, this study aims to analyze these four major chain convenience stores systems, according to the "number of stores", 


\section{Macrothink}

"number of employees", "capital" and "revenue". Moreover, all the data are updated to the year 2016. Specifically, the number of stores is obtained from the statistical results of the Department of Commerce, the Ministry of Economic Affairs of Taiwan. The number of employees and the capital of companies get from the private 1111 Job Bank in Taiwan. The revenue is obtained from the information published by the individual official website of each chain convenience store. The details of data are summarized in Table 1.

According to data in Table 1, the "DEA Solver" software is then deployed to analyze the efficiency of the four major convenience stores, under the optimal method of CCR. Moreover, for the definition of variables, number of stores is set as "Input1", number of employees is set as "Input2", capital is set as "Input3", and finally the revenue is set as "Output". The analysis results show that 7-Eleven is the most efficient company. In addition, the other three chain convenience stores compared with 7-Eleven' inputs and output are shown in Figure 2, Figure 3 and Figure 4, respectively.

Table 1. Operating facts of four major chain convenience stores

\begin{tabular}{lllll}
\hline Brand & Stores $^{(1)}$ & Employees $^{(2)}$ & $\begin{array}{l}\text { Capital }^{(2)} \\
\text { (billion NTD) }\end{array}$ & $\begin{array}{l}\text { Revenue }^{(3)} \\
\text { (billion NTD) }\end{array}$ \\
\hline 7-Eleven & 5,125 & 7,775 & 4.2 & 215.359 \\
FamilyMart & 3,003 & 4,288 & 2.1 & 60.567 \\
Hi-Life & 1,340 & 3,128 & 1.856 & 30.258 \\
OK-Mart & 798 & 1,010 & 1.8 & 15.427 \\
\hline
\end{tabular}

Source: (1) Department of Commerce, Ministry of Economic affairs, Taiwan.

(2) 1111Job Bank.

(3) Official websites of individual brands.

From Figure 2, it is obviously that efficiency of the number of stores of FamilyMart is about $59 \%$ of the 7-Eleven, while the number of employees is about $45 \%$, capital is about $50 \%$, and revenue is about $38 \%$ of 7 -Eleven. Therefore, compared with the investment of 7 -Eleven, FamilyMart has a space for expansion on the number of employees and amount of capital. 


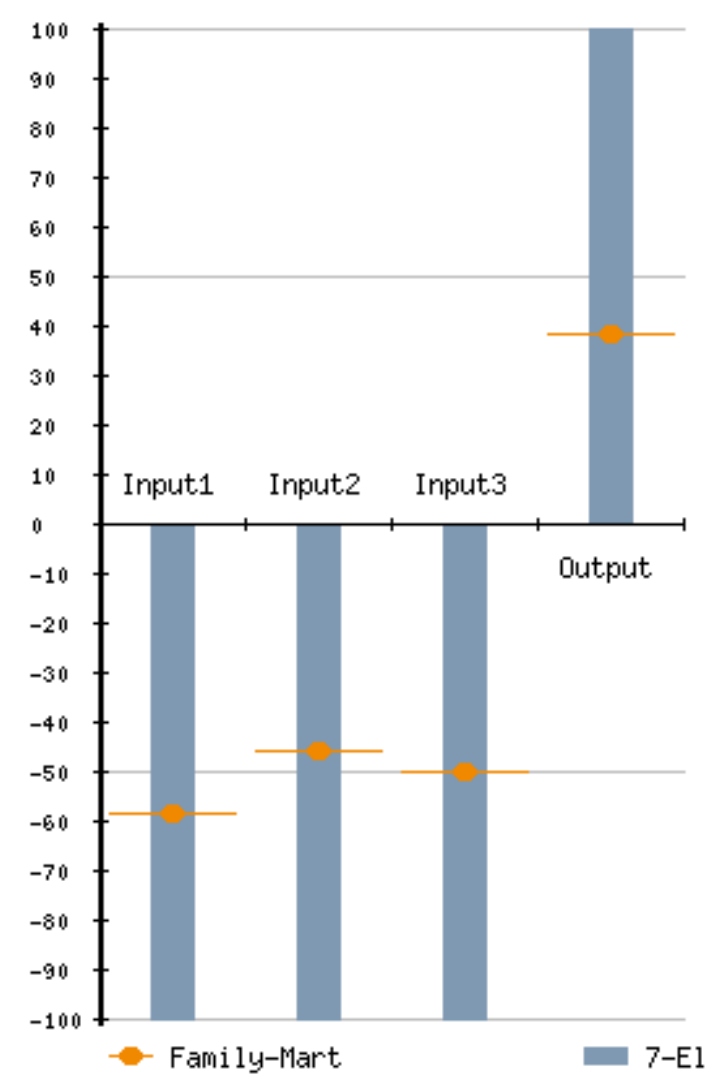

Figure 2. Comparisons of Input-Output Efficiency between FamilyMart and 7-Eleven

Figure 3 shows the efficiency of the number of stores of Hi-Life is about $27 \%$ of the 7 -Eleven, and the number of employees is about $35 \%$, capital is about $45 \%$, while revenue is only about $15 \%$ of 7 -Eleven. Therefore, compared with the investment of 7-Eleven, Hi-Life has a significant expansion space on the number of stores, the number of employees and capital, especially for the number of stores. 


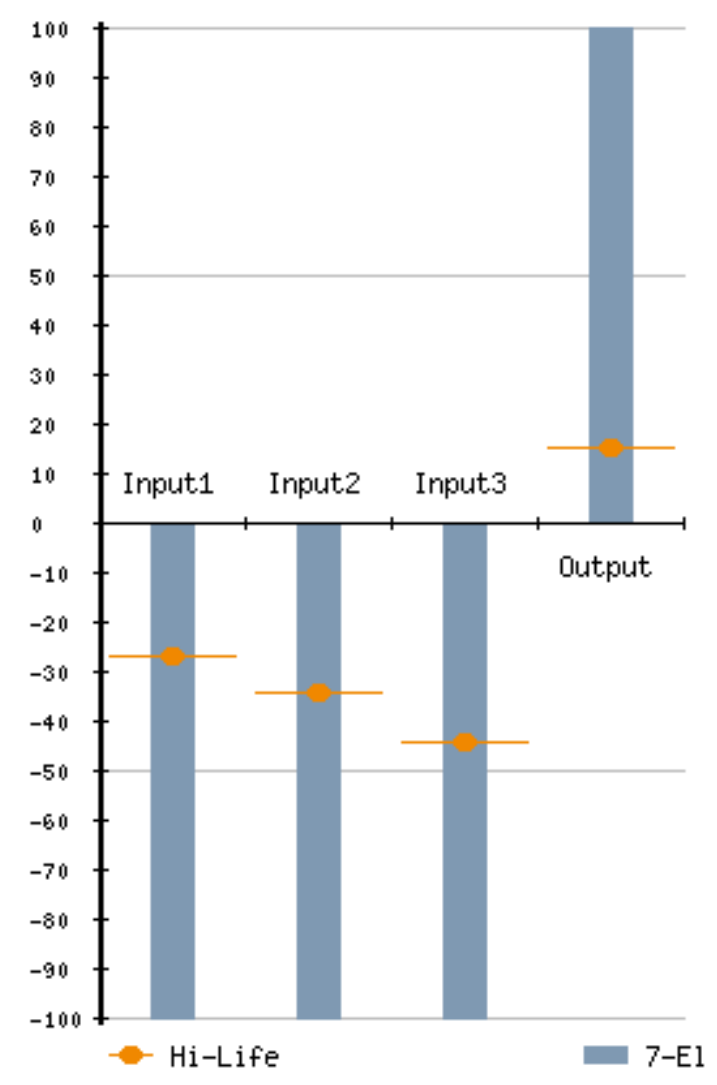

Figure 3. Comparisons of Input-Output Efficiency between Hi-life and 7-Eleven

Moreover, Figure 4 shows that the efficiency of number of OK-Mart is about $19 \%$ of the 7 -Eleven, and number of employees is about $14 \%$, capital is about $44 \%$, while revenue is only about $10 \%$ of 7 -Eleven. Therefore, compared with the investment of 7-Eleven, OK-Mart has a significant expansion space for the number of stores, the number of employees and capital, especially for the number of stores and the number of employees. 


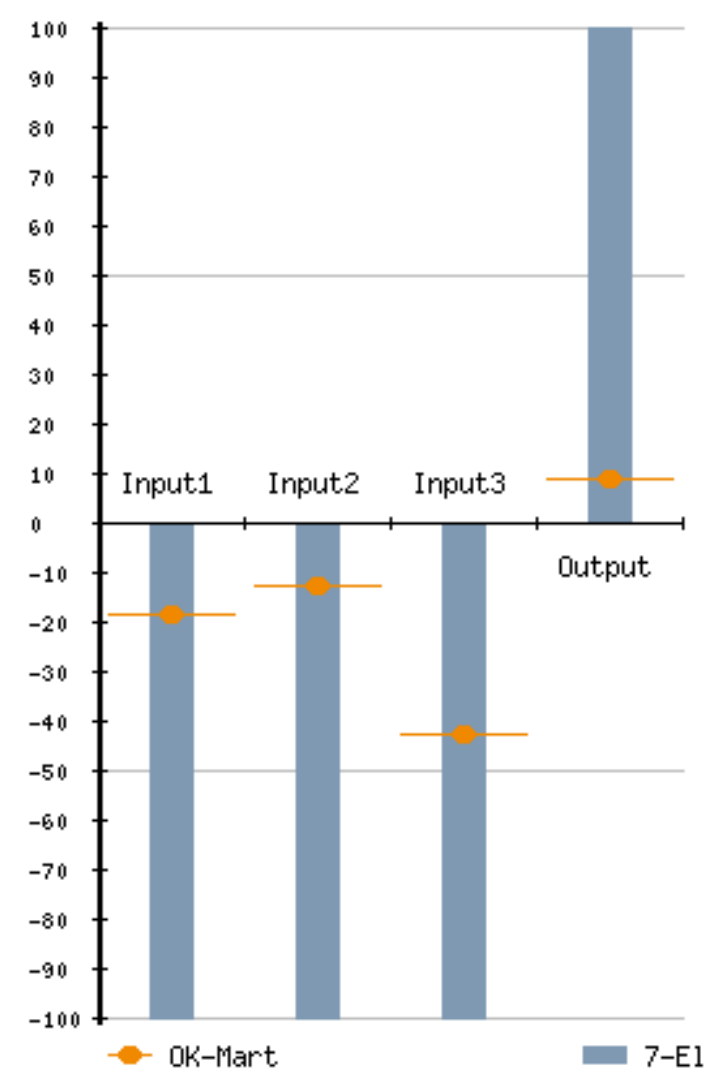

Figure 4. Comparisons of Input-Output Efficiency between OK-Mart and 7-Eleven

Finally, the results of the overall operating efficiency are shown in Table 2. 7-Eleven has the highest efficiency among the four chain convenience stores, with the relative efficiency of 1 $(100 \%)$; then followed by FamilyMart, with the relative efficiency compared with 7-Eleven is about $85 \%$; OK-Mart, with relative efficiency compared with 7 -Eleven is about $70 \%$; and the last one is Hi-Life, with relative efficiency compared with 7 -Eleven is only about $56 \%$.

Table 2. Relative operational performances of chain convenience stores

\begin{tabular}{lll}
\hline Brand & Relative un-efficiency & Relative efficiency \\
\hline 7-Eleven & 0.000000 & 1.000000 \\
FamilyMart & 0.152126 & 0.847874 \\
Hi-Life & 0.435700 & 0.564300 \\
OK-Mart & 0.299934 & 0.700066 \\
\hline
\end{tabular}

In summary, according to the results of DEA efficiency analysis, the sequence of operating 
efficiency ranking for four chain convenience stores is 7-Eleven, FamilyMart, OK-Mart, and Hi-Life. It is interesting that the scale of the OK-Mart is ranked fourth in the industry, however, OK-Mart gets a higher operating efficiency than Hi-Life that ranked third in the industry. The reason is that, compared with Hi-Life, OK-Mart owns relatively few numbers of stores and employees, but can still get the considerable revenue.

\section{Conclusions}

This study explores the operating efficiency of the four major chain convenience stores in Taiwan by means of data envelopment analysis. It shows that 7-Eleven has the highest relative efficiency among the four chain convenience stores; thereafter followed by FamilyMart, it has a relative efficiency of about $85 \%$ of 7 -Eleven; then OK-Mart, it has a relative efficiency of about $70 \%$ of 7 -Eleven. Finally, Hi-Life comes last, with about $56 \%$ relative efficiency of 7-Eleven. According to the results of the efficiency analysis, the ranking of the operational efficiency of the four major convenience stores is 7-Eleven, FamilyMart, OK-Mart, and Hi-Life.

To be noticed, considering the operation scale, OK-Mart is ranked fourth in the industry; however, it obtains a higher operating efficiency than Hi-Life that ranked third in the industry. That means even OK-Mart keeps relatively few numbers of stores and employees, but can still get the considerable revenue.

As for further studies, there are three recommendations. First, this study focus only on Taiwan's four major chain convenience stores, thus the number of decision-making units is somewhat inadequate. It is recommended that the future study can include more other chain convenience stores to get better efficiency analysis results. Moreover, this study applies the basic fixed input-output CCR model for efficiency evaluation. The future study can try to analyze the BCC model with non-fixed inputs and outputs to get more detailed analysis results. Finally, this study defines "number of stores," "number of employees," "capital" as input variables, and "revenue" as the output variable. However, it is also recommended that the future study may try to increase or decrease this variable setting if needed.

\section{References}

Commerce information intelligence service, Department of Commerce, Ministry of Economic Affairs, Taiwan. Retrived from http://ciis.cdri.org.tw

Eilat, H., Golany, B., \& Shtub, A. (2006). Constructing and evaluating balanced portfolios of R\&D projects with interactions: a DEA based methodology. European Journal of Operational Research, 172, 1018-1039. https://doi.org/10.1016/j.ejor.2004.12.001

Hamdan, A., \& Rogers, K. J. (2008). Evaluating the efficiency of 3PL logistics operations. International Journal of Production Economics, 113, 235-244. https://doi.org/10.1016/j.ijpe.2007.05.019

Hosseinzadeh, A., Smyth, R., Valadkhani, A., \& Le, V. (2016). Analyzing the efficiency performance of major Australian mining companies using bootstrap data envelopment analysis. Economic Modelling, 57, 26-35. https://doi.org/10.1016/j.econmod.2016.04.008 


\section{Macrothink}

Journal of Social Science Studies

ISSN 2329-9150 2018, Vol. 5, No. 1

Ramanathan, R. (2001). Comparative risk assessment of energy supply technologies: a data $\begin{array}{lllll}\text { envelopment } \quad \text { analysis } & \text { approach. }\end{array}$ https://doi.org/10.1016/S0360-5442(00)00058-X

Saha, A., \& Ravisankar, T. S. (2000). Rating of Indian commercial banks: a DEA approach. European Journal of Operational Research, 124, 187-203. https://doi.org/10.1016/S0377-2217(99)00167-8

Sathye, M. (2003). Efficiency of banks in a developing economy: the case of India. European Journal of Operational Research, 148, 662-671. https://doi.org/10.1016/S0377-2217(02)00471-X

Taylor III, B. W. (2009). Introduction to management science (10th ed.), Pearson.

\section{Copyright Disclaimer}

Copyright for this article is retained by the author(s), with first publication rights granted to the journal.

This is an open-access article distributed under the terms and conditions of the Creative Commons Attribution license (http://creativecommons.org/licenses/by/3.0/). 